\title{
A Comparison of Nannochloropsis salina Growth Performance in Two Outdoor Pond Designs: Conventional Raceways versus the ARID Pond with Superior Temperature Management
}

\author{
Braden Crowe, ${ }^{1}$ Said Attalah, ${ }^{2}$ Shweta Agrawal, ${ }^{3}$ Peter Waller, ${ }^{2}$ \\ Randy Ryan, ${ }^{4}$ Jon Van Wagenen, ${ }^{1}$ Aaron Chavis, ${ }^{1}$ John Kyndt, ${ }^{5}$ Murat Kacira, ${ }^{2}$ \\ Kim L. Ogden, ${ }^{3}$ and Michael Huesemann ${ }^{1}$ \\ ${ }^{1}$ Marine Sciences Laboratory, Coastal Biogeochemistry Group, Pacific Northwest National Laboratory, Sequim, WA 98382, USA \\ ${ }^{2}$ Department of Agricultural and Biosystems Engineering, The University of Arizona, Tucson, AZ 85721, USA \\ ${ }^{3}$ Department of Chemical and Environmental Engineering, The University of Arizona, Tucson, AZ 85721, USA \\ ${ }^{4}$ College of Agriculture, The University of Arizona, Tucson, AZ 85721, USA \\ ${ }^{5}$ Department of Chemistry and Biochemistry, The University of Arizona, Tucson, AZ 85721, USA
}

Correspondence should be addressed to Michael Huesemann, michael.huesemann@pnnl.gov

Received 3 December 2011; Revised 11 March 2012; Accepted 14 March 2012

Academic Editor: Jose C. Merchuk

Copyright (C) 2012 Braden Crowe et al. This is an open access article distributed under the Creative Commons Attribution License, which permits unrestricted use, distribution, and reproduction in any medium, provided the original work is properly cited.

\begin{abstract}
The present study examines how climatic conditions and pond design affect the growth performance of microalgae. From January to April of 2011, outdoor batch cultures of Nannochloropsis salina were grown in three replicate $780 \mathrm{~L}$ conventional raceways, as well as in an experimental $7500 \mathrm{~L}$ algae raceway integrated design (ARID) pond. The ARID culture system utilizes a series of 8-20 cm deep basins and a $1.5 \mathrm{~m}$ deep canal to enhance light exposure and mitigate temperature variations and extremes. The ARID culture reached the stationary phase 27 days earlier than the conventional raceways, which can be attributed to its superior temperature management and shallower basins. On a night when the air temperature dropped to $-9^{\circ} \mathrm{C}$, the water temperature was $18^{\circ} \mathrm{C}$ higher in the ARID pond than in the conventional raceways. Lipid and fatty acid content ranged from 16 to $25 \%$ and from 5 to $15 \%$, respectively, as a percentage of AFDW. Palmitic, palmitoleic, and eicosapentaenoic acids comprised the majority of fatty acids. While the ARID culture system achieved nearly double the volumetric productivity relative to the conventional raceways $\left(0.023\right.$ versus $\left.0.013 \mathrm{~g} \mathrm{~L}^{-1} \mathrm{day}^{-1}\right)$, areal biomass productivities were of similar magnitude in both pond systems (3.47 versus $3.34 \mathrm{~g} \mathrm{~m}^{-2} \mathrm{day}^{-1}$ ), suggesting that the ARID pond design has to be further optimized, most likely by increasing the culture depth or operating at higher cell densities while maintaining adequate mixing.
\end{abstract}

\section{Introduction}

Raceway ponds have been commonly used as microalgae production systems since the 1970s [1]. Their simplicity and low costs have led to their adoption in commercial microalgae production systems [2]. The conventional design utilizes a motor driven paddle wheel to propel the culture around a circular track. Many variations on this basic pond design have been explored, and there have been efforts to combine conventional raceways with photobioreactors in a two-stage cultivation process [3-5]. Given that microalgae-derived biofuels have yet to be proven economically feasible on an industrial scale, all aspects of the production chain require further optimization. Cultivation system optimization could lead to more favorable economics by raising annual biomass yields and reducing capital and operating costs.

In an outdoor production environment, both conventional raceways and photobioreactors are subject to inclement weather that can create suboptimal growth conditions. Any attempt to control or mitigate temperature extreme can decrease the net energy output of the production system and increase capital costs. Temperature control systems must therefore be inexpensive, high-impact, and scalable. Current methods of temperature control include 


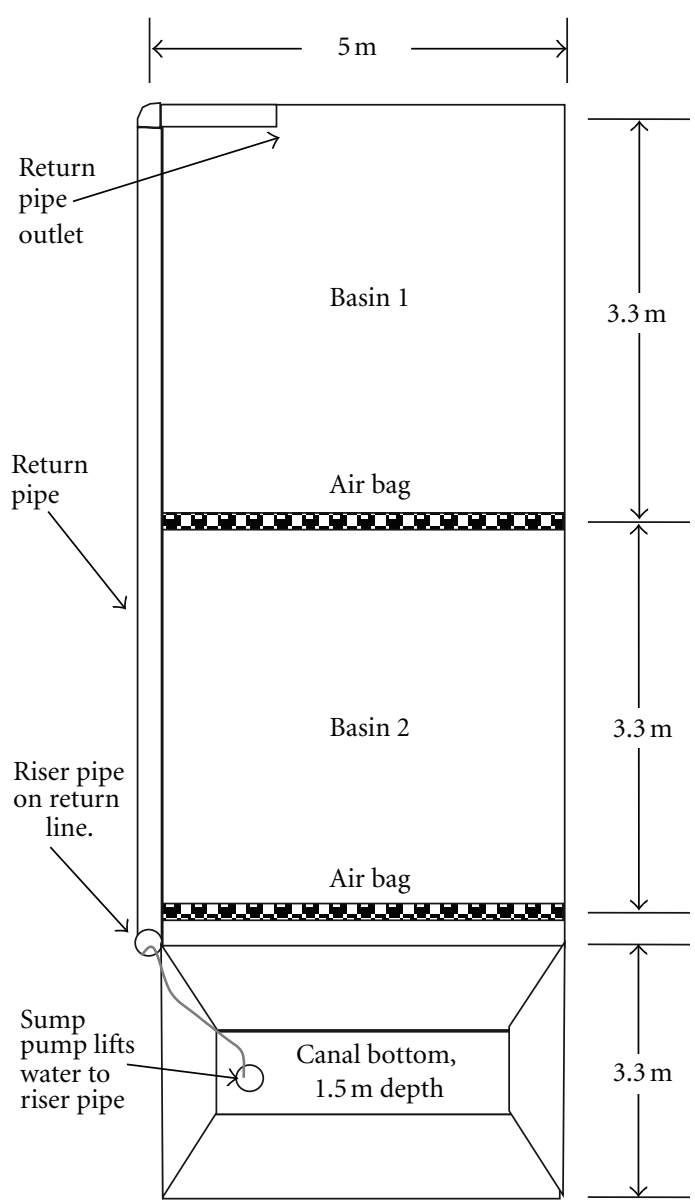

(a)

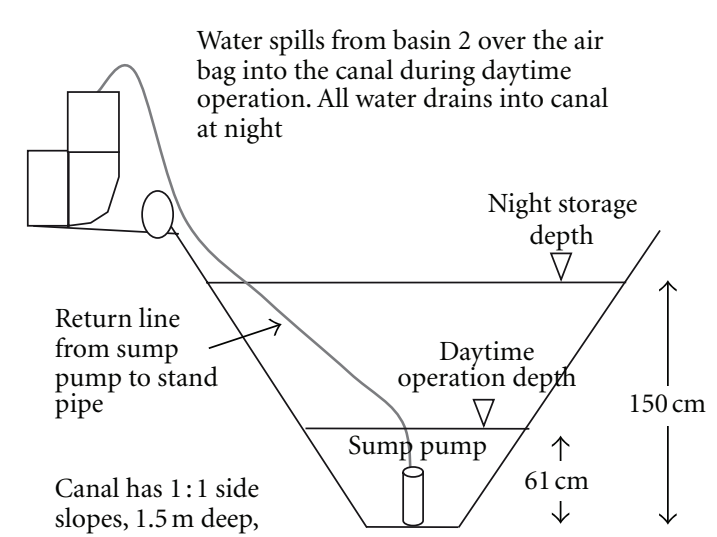

(b)

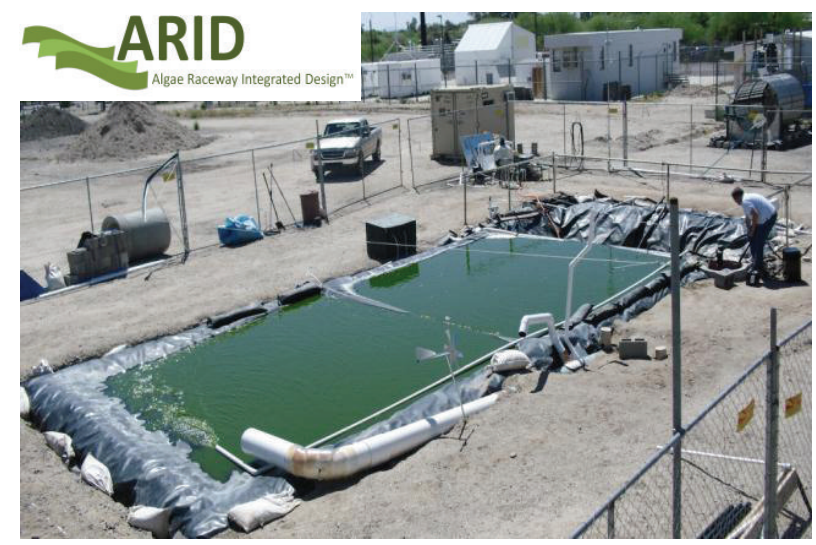

(c)

FIgURE 1: (a) ARID pond schematic. (b) Detail of ARID pond canal, showing water depths during day and night operation. (c) Photo from $N$. salina batch culture study.

spraying photobioreactors and open ponds with water for convective cooling or covering with an insulating material during winter [3]. These methods increase operating costs and may not be practical on an industrial scale. However, without improvements in temperature management, the regions where algae cultivation is practical may be severely limited.

The algae raceway integrated design (ARID) pond was developed to enable cost-effective microalgae cultivation in regions that experience extreme temperature fluctuations [6]. ARID is a patented algae cultivation system designed to maximize productivity with minimal energy use by controlling pond water temperature variations and optimizing sunlight exposure $[6,7]$.

In the current study, we compare the performance of the ARID culture system with conventional raceways in a desert climate during winter conditions. The purpose of this study was to determine if water temperatures can be significantly increased in the ARID pond and whether this results in increased biomass and lipid productivities.

\section{Materials and Methods}

The marine microalgae Nannochloropsis salina (CCMP 1776) was cultured in two outdoor pond systems: the ARID pond (Figure 1(a)) and triplicate conventional, paddle-wheel driven raceways (Figure 2(a)) from January to April 2011 in Tucson, AZ, USA. Table 1 compares culture system specifications and designs. The ARID pond operation is described in detail by Waller et al. [7] and summarized briefly here. The thermal management strategy is similar to that presented by Setlik et al. [8] and consists of a shallow region with high surface area to enhance light exposure combined with a deeper second section of high volume and low surface area for thermal conservation. During the day, a sump pump in the deep canal (Figure 1(b)) circulates culture into Basin 1. The culture then flows over a series of airbags into Basin 2 and eventually back into the $1.5 \mathrm{~m}$ deep canal for recirculation. In the evening, when incident light intensity decreases below a set point, the sump pump deactivates and airbags deflate to allow the culture to drain into the narrow canal, thereby reducing the overall surface area of the 


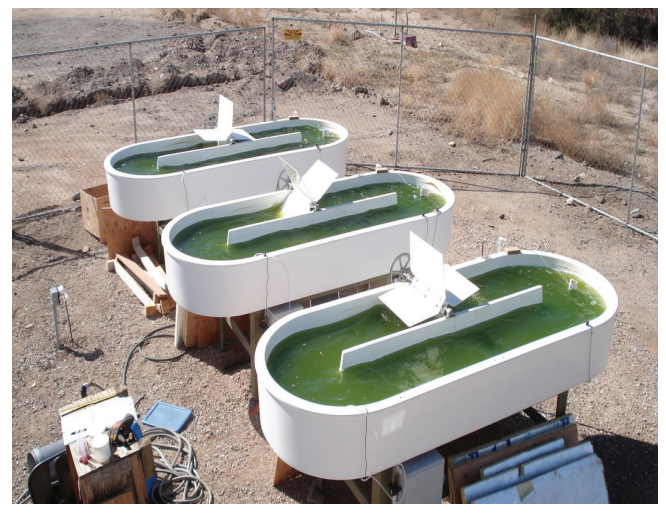

(a)

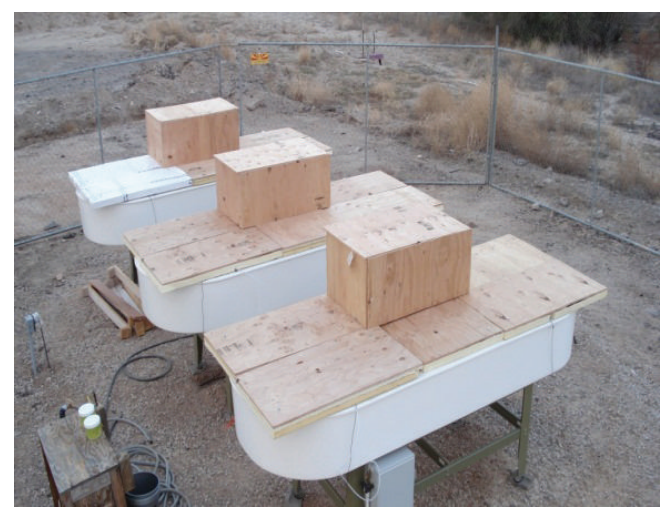

(c)

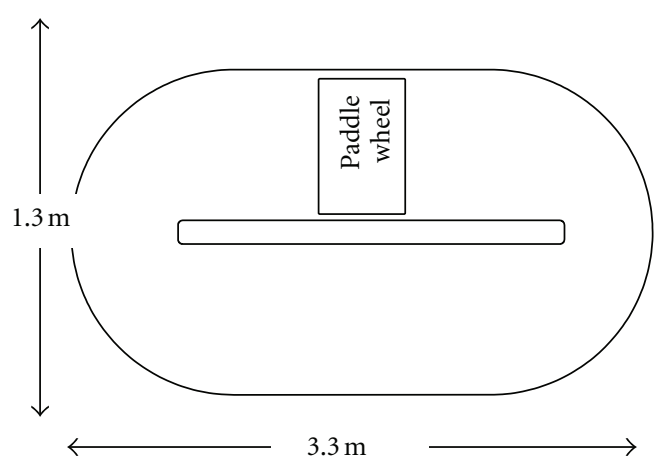

(b)

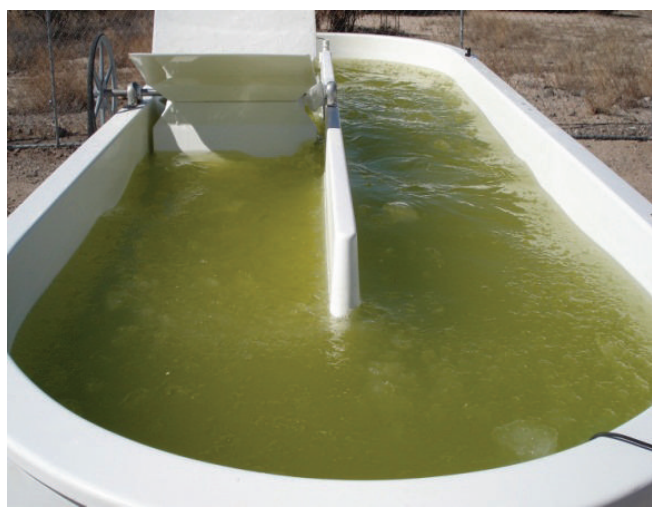

(d)

Figure 2: (a) Conventional raceways 26 days after inoculation on 2/21/2011. (b) Raceway schematic and dimensions. (c) Night-time operation. (d) Ice slurry after record lows on 2/3/11.

TABLE 1: ARID pond and conventional raceway characteristics.

\begin{tabular}{|c|c|c|}
\hline & Conventional Raceways & ARID Pond \\
\hline Volume & $780 \mathrm{~L}$ (each) & $7500 \mathrm{~L}$ \\
\hline Surface area & $3 \mathrm{~m}^{2}$ & $50 \mathrm{~m}^{2}$ \\
\hline Surface area: volume ratio & $1: 260$ & $1: 150$ \\
\hline Culture depth & $25.4 \mathrm{~cm}$ & $\begin{array}{l}\text { Basin 1: up to } 15 \mathrm{~cm} \\
\text { Basin 2: } 20 \mathrm{~cm} \\
\text { Canal (day): } 60 \mathrm{~cm} \\
\text { Canal (night): } 150 \mathrm{~cm}\end{array}$ \\
\hline Mixing & Paddle wheel rotating at $6 \mathrm{rpm}$ & $\begin{array}{l}\text { Gravity driven flow from top } \\
\text { basin to canal. Aeration at night }\end{array}$ \\
\hline Current velocity & $0.25 \mathrm{~m} \mathrm{~s}^{-1}$ & $0.003 \mathrm{~m} \mathrm{~s}^{-1}$ \\
\hline Reynolds number* & 26906 & 407 \\
\hline Evaporation & Corrected daily before sampling & $\begin{array}{l}\text { Corrected every } 2-3 \text { days to } \\
\text { maintain salinity at } 35 \mathrm{ppt}\end{array}$ \\
\hline Temperature management & Covered at dusk, uncovered in morning. & $\begin{array}{l}\text { Storage of culture in canal at } \\
\text { night, circulated in basins during } \\
\text { the day }\end{array}$ \\
\hline
\end{tabular}

\footnotetext{
* Assumed rectangular open-channel flow, with the characteristic length defined as the cross-sectional area divided by its wetted perimeter. For the conventional raceways, the cross-section height was taken as the culture depth $(0.25 \mathrm{~m})$ and its width as $0.53 \mathrm{~m}$. For the ARID pond, the average culture depth $(0.175 \mathrm{~m})$ in the shallow basins was taken for the cross-sectional area height and $5 \mathrm{~m}$ for the channel width, estimated with kinematic viscosity of saltwater at $35 \mathrm{ppt}$ and $15^{\circ} \mathrm{C}, 1.205 \mathrm{e}-6 \mathrm{~m}^{2} \mathrm{~s}^{-1}$.
} 
culture that is in contact with the ambient cold environment during the night. Figure 1(c) displays the daytime ARID pond operation. On nights when the ambient temperature decreased below $10^{\circ} \mathrm{C}$, the conventional raceways were covered with $7.6 \mathrm{~cm}$ thick foam insulation (Figure 2(c)).

The cultures were grown in $\mathrm{f} / 2-\mathrm{Si}$ artificial seawater media enriched with $4 \mathrm{mM} \mathrm{N}$ and $0.1 \mathrm{mM} \mathrm{P}$ [9]. Instant Ocean [10] was added to achieve a salinity of $35 \mathrm{ppt}$, with make-up water added as needed to maintain constant pond water depth. The ponds were supplied with pure $\mathrm{CO}_{2}$ to maintain the culture $\mathrm{pH}$ between 7 and 7.5. Pond water temperatures were recorded every 5 minutes in the conventional raceways. The ARID pond water temperature was recorded from Basin 2 during daytime operation and in the deep canal during the night. Incident light intensity as photosynthetically active radiation (PAR) and solar radiation were recorded every minute with a LiCor (LI-1400) data logger equipped with a LI-190 SA quantum sensor and a LI200 pyranometer, respectively. Daily net photon and energy flux were calculated by numerical integration. Samples from both ponds were inspected weekly with a microscope at 400 times magnification for the potential presence of invasive species. Samples were frozen at $-20^{\circ} \mathrm{C}$ until lyophilization for ash, moisture, lipid, and fatty acid content analysis.

Biomass concentrations were monitored both photospectrometrically as optical density (OD at $750 \mathrm{~nm}$ ) and gravimetrically as ash-free dry weight (AFDW), as described in Huesemann et al. [11]. The AFDW procedure also included an isotonic ammonium formate rinse $(20 \mathrm{~mL}$, $0.5 \mathrm{M})$ to remove culture media salts after vacuum filtration of the cell culture sample. AFDW data were averaged for the three conventional raceways, with error bars denoting one standard deviation from the mean. Medium nitrate and phosphate concentrations were quantified using the Hach NitraVer5 (Method 8039) and PhosVer3 (Method 8048) colorimetric assays $[12,13]$ using filtrate collected during the AFDW procedure.

For the determination of water and ash content, 6-12 mg of freeze-dried biomass $\left(M_{0}\right)$ were placed on a preashed aluminum foil weigh boat and weighed $\left(M_{1}\right)$ and then dried at $100^{\circ} \mathrm{C}$ for at least 12 hours. After weighing $\left(M_{2}\right)$, samples were heated at $540^{\circ} \mathrm{C}$ to combust all organic carbon, with the weight of the foil weigh boat and inorganic residues noted as $\left(M_{3}\right)$. Water and ash content $(\mathrm{w} / \mathrm{w})$ were then determined by dividing the respective weight difference $\left(M_{1}-M_{2}\right) / M_{0}$ and $\left(M_{2}-M_{3}\right) / M_{0}$.

Total lipids (polar, neutral, and nonpolar) were extracted from microalgae biomass using a procedure adapted from Bligh and Dyer [14]. Lipids were extracted from at least $30 \mathrm{mg}$ of freeze-dried biomass in a mixture of methanol:chloroform: water $(10: 5: 4, \mathrm{v} / \mathrm{v})$. Following the overnight mixing, solvent ratios were adjusted to $10: 10: 9$, v/v. The extract was transferred to a preweighed glass vial, placed in a water bath for chloroform evaporation, and then dried in a $100^{\circ} \mathrm{C}$ oven for 1 hour before taking the final lipid weight measurement. Triplicate culture samples were taken on March 4th and April 26th from the conventional raceways in order to assess the reproducibility of lipid, ash, and moisture analyses. The lipid content was calculated by dividing the lipid mass by the ash- and water-corrected weight of freeze dried biomass. Lipid concentration was calculated by multiplying the biomass concentration by the lipid content.

Transesterification was performed by adding $2.5 \%$ sulfuric acid in methanol to freeze-dried biomass spiked with a heneicosanoic acid surrogate and incubating at $90^{\circ} \mathrm{C}$ for one hour under nitrogen. Fatty acid methyl esters (FAMEs) were extracted in hexane [15] and spiked with methyl heptadecanoate as an internal standard and stored at $-20^{\circ} \mathrm{C}$ until analysis. FAMEs were separated by gas chromatography (Hewlett Packard 5890A) in a SP-2380 capillary column (length $=60 \mathrm{~m}$, inside diameter $=0.25 \mathrm{~mm}$, film thickness $=$ $0.2 \mu \mathrm{m}$ ) with a flame ionization detector (GC-FID). Helium was used as the carrier gas with an injector and FID temperature of $250^{\circ} \mathrm{C}$, with the oven ramping from $50^{\circ} \mathrm{C}$ to $250^{\circ} \mathrm{C}$ at a rate of $5^{\circ} \mathrm{C} \mathrm{min}^{-1}$. Quantification was performed relative to a marine oil FAME mix (Restek) standard, and yield was calculated from the ratio of surrogate $(\mathrm{C} 21)$ to internal standard (C17). Fatty acid content as a percentage of AFDW was determined by dividing the sum of all identified fatty acid components by the moisture- and ashcorrected freeze-dried biomass weight. Triplicate samples were analyzed on March 4th and April 26th to assess FAMEs consistency between the conventional raceways.

Volumetric biomass productivity is defined as the change in biomass weight per unit volume per day and was calculated for each pond design from the onset of exponential growth (an increase of 5\% above lag phase biomass concentration) until reaching $95 \%$ of the stationary phase concentration. Volumetric lipid productivity was calculated by taking the difference between the product of the biomass concentration and lipid content at final and initial time points and dividing by the time period. Areal productivity was calculated by multiplying the volumetric productivity by the culture volume and dividing by the pond reactor surface area.

\section{Results}

The temperature management system of the ARID pond enabled better temperature control and modulation of environmental extremes, with the average temperature of the ARID system being $9.5^{\circ} \mathrm{C}$ higher than in the conventional raceways over its batch growth $(1 / 27-3 / 14)$ period. The daily average, minimum, and maximum water temperatures of the ARID pond and the conventional raceways during batch growth are shown in Figure 3. The average daily ambient temperature during the study was $15^{\circ} \mathrm{C}$, with average diurnal temperature fluctuations of $20^{\circ} \mathrm{C}$. Daily minimum pond water temperatures of the ARID system regularly exceeded the daily maximum observed water temperature in the conventional raceways. The average temperature in the ARID pond culture was $19.5^{\circ} \mathrm{C}$ throughout its batch growth phase $(1 / 27-3 / 14)$, compared to $10.5^{\circ} \mathrm{C}$ in the conventional raceways over the same period, and $13.2^{\circ} \mathrm{C}$ over the entire experiment (until 4/26). Although the pond water temperature varied significantly between the two 


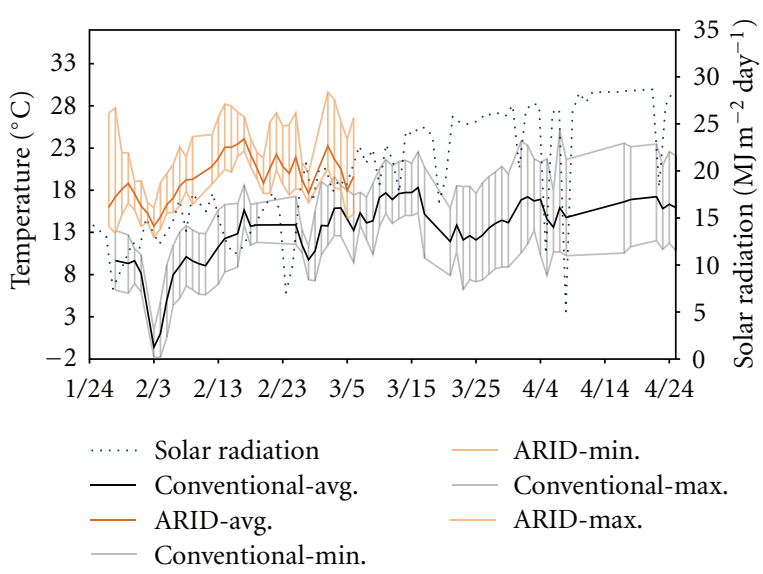

FIgURE 3: Daily ARID pond and conventional raceway water temperature average, minimum, and maximum and daily solar radiation.

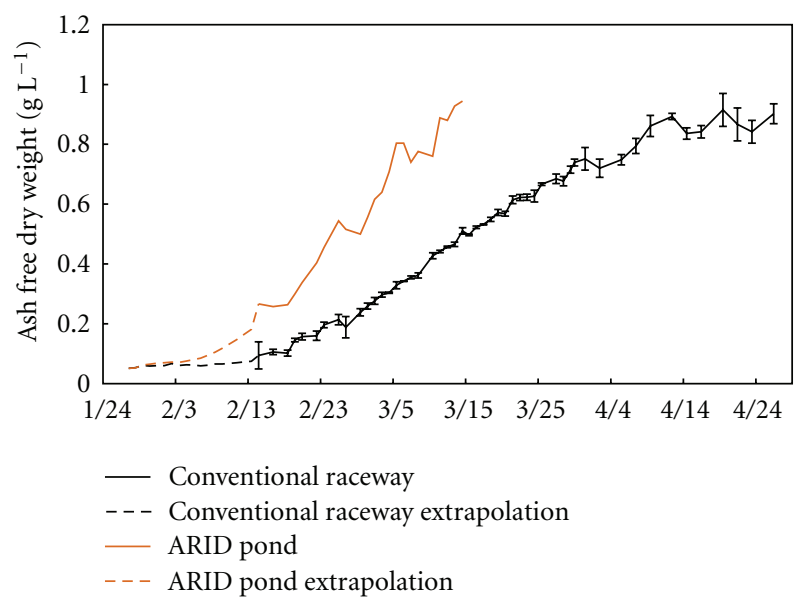

FIgURE 4: AFDW as a function of time for the ARID pond and triplicate conventional raceways. Batch phase growth ended on $3 / 14$ for the ARID pond and 4/26 for the conventional raceways. The dashed regions were extrapolated with an $\mathrm{OD}_{750}$ to AFDW correlation equation $\left(\mathrm{AFDW}=0.225\left(\mathrm{OD}_{750}\right)+0.036\right)$ with an $R^{2}=$ 0.98 .

designs, incident light intensity (PAR) was the same, reaching up to $2000 \mu \mathrm{mol} \mathrm{m}^{-2} \mathrm{~s}^{-1}$ on clear, sunny days. Daily solar radiation is reported in Figure 3, which averaged $30.7 \mathrm{~mol}$ quanta $\mathrm{m}^{-2}$ day $^{-1}$ over the ARID culture growth period and $38.7 \mathrm{~mol}$ quanta $\mathrm{m}^{-2}$ day $^{-1}$ during batch growth in the conventional raceways. Generally, days with high solar radiation corresponded to warmer pond water temperatures.

Given the ARID pond's superior temperature management, biomass productivity differed in the two culture systems. Figure 4 shows the biomass concentration (AFDW) as a function of time. Both pond systems reached similar maximum biomass densities of $944 \mathrm{mg} \mathrm{L}^{-1}$ (ARID, 3/14) and $904 \mathrm{mg} \mathrm{L}^{-1}$ (conventional, 4/26), although the ARID pond reached $95 \%$ of its stationary phase concentration 27 days before the conventional raceways. Phosphate levels reached a minimum on 2/25 in both raceways (Figure 5). The lowest

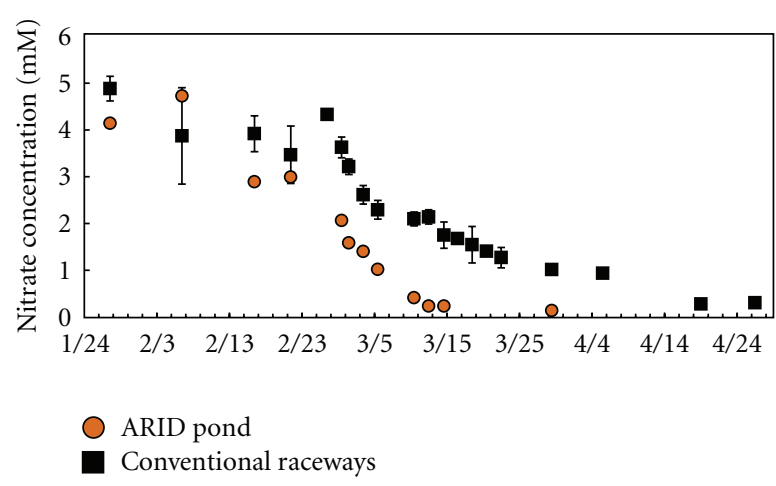

FIGURE 5: Culture media nitrate concentration as a function of time for the ARID pond and triplicate conventional raceways.

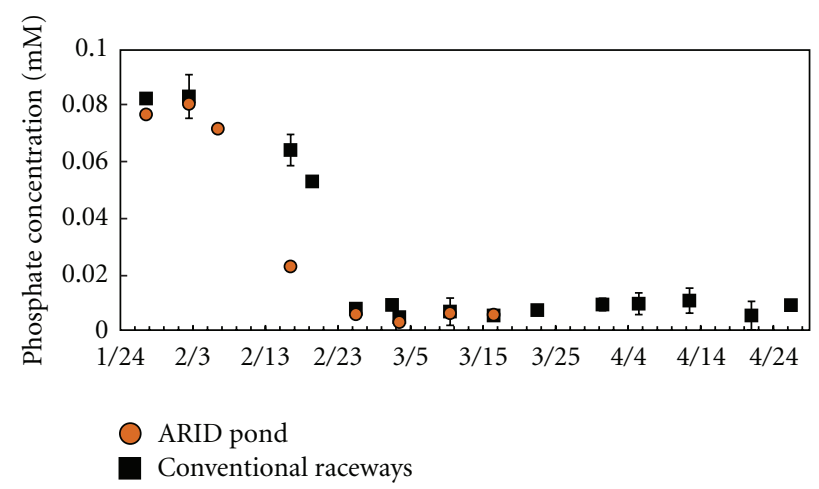

FIGURE 6: Culture media phosphate concentration as a function of time for the ARID pond and triplicate conventional raceways.

recorded nitrogen concentrations of $0.24 \mathrm{mM}$ (ARID, 3/12) and $0.29 \mathrm{mM}$ (conventional, 4/19) coincide with the onset of the stationary phase in both ponds (Figures 4 and 6). Table 2 summarizes the areal and volumetric biomass and lipid productivities. The ARID pond achieved nearly double the volumetric biomass productivity relative to the conventional raceways $\left(0.023\right.$ versus $\left.0.013 \mathrm{~g} \mathrm{~L}^{-1} \mathrm{day}^{-1}\right)$, although areal productivities in both culture systems were similar at 3.47 and $3.34 \mathrm{~g} \mathrm{~m}^{-2}$ day $^{-1}$, respectively.

Weekly microscopic examination confirmed that $N$. salina remained the dominant species throughout the study. A motile invasive species with a $4-7 \mu \mathrm{m}$ cell diameter was occasionally observed in the conventional raceways. A white substance was detected in the centrifugation pellets of samples taken from the conventional raceways, possibly silt or cell fragments from cell lysis. The ARID pond contained fewer debris and invasive species than the conventional raceways.

Total lipids and FAMEs content as a percentage of AFDW for the two cultivation systems are shown in Figure 7. Lipid content ranged from 15 to $25 \%$ in both culture systems, with slightly increased levels observed in the conventional raceways. In the conventional raceways, lipid content generally stabilized between 23 and $25 \%$ after 3/4, while in the ARID culture there was no consistent trend. Despite its slightly higher lipid contents, the conventional raceway 
TABLE 2: ARID and conventional raceway biomass and lipid productivity.

\begin{tabular}{lcc}
\hline & Conventional raceways & ARID pond \\
\hline Volumetric biomass productivity, $\mathrm{g} \mathrm{L}^{-1}$ day $^{-1}$ & 0.013 & 0.023 \\
Areal biomass productivity, $\mathrm{g} \mathrm{m}^{-2} \mathrm{day}^{-1}$ & 3.34 & 3.47 \\
Volumetric lipid productivity, $\mathrm{g} \mathrm{L}^{-1} \mathrm{day}^{-1}$ & 0.003 & 0.006 \\
Areal lipid productivity, $\mathrm{g} \mathrm{m}^{-2}$ day $^{-1}$ & 0.82 & 0.94 \\
\hline
\end{tabular}

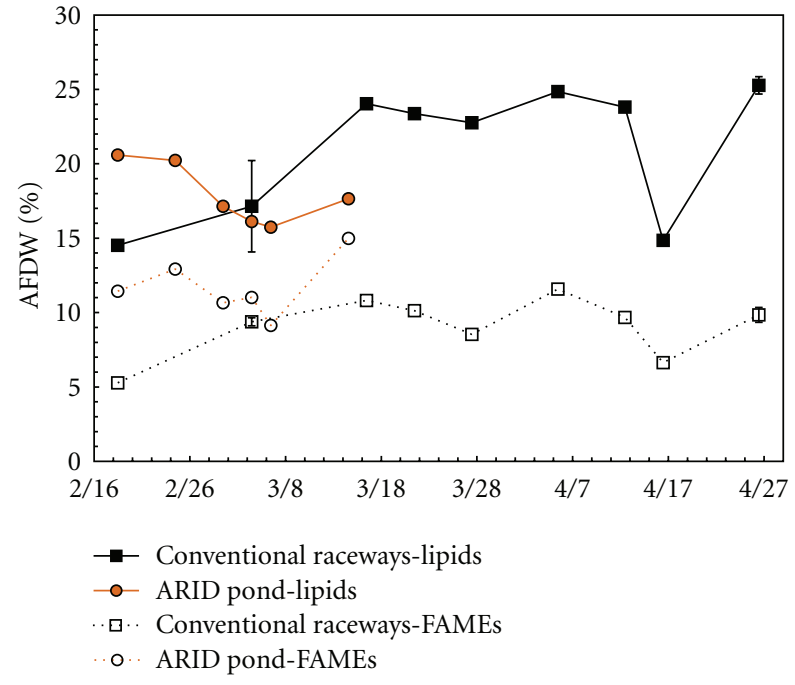

FIGURE 7: Lipid and FAME content of the ARID pond and conventional raceways, expressed as a percentage of AFDW.

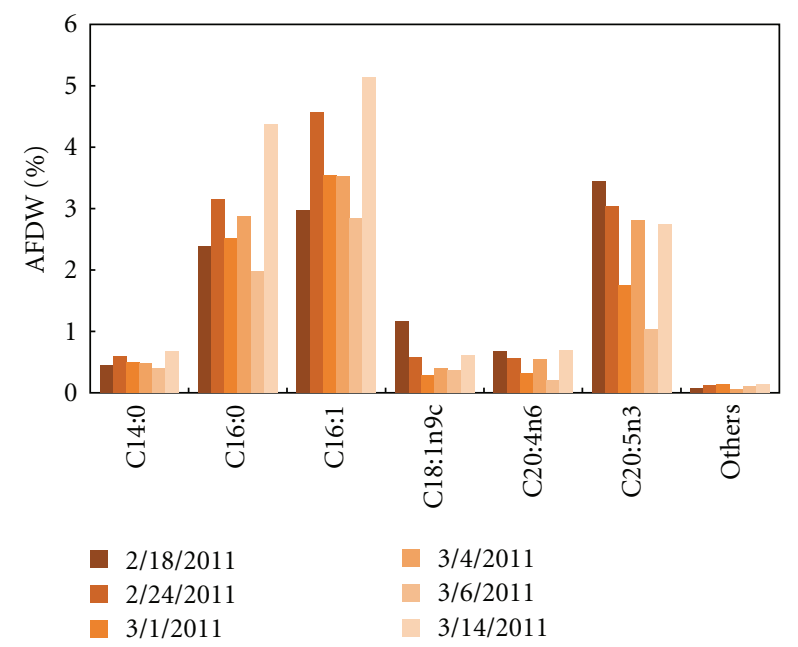

FIGURE 8: FAME composition of the ARID culture, as a percentage of ash free dry weight. The Others category includes C14:1, C20:0, C18:0, C18:1, C18:2n6c, C20:1, C18:3n3, C20:2, C22:0, C22:1n9, C20:3n3, C24:1, C22:6n3, and C24:0.

biomass was characterized by lower FAME content. As a result, the lipids in the conventional raceway cultures contained a lower proportion of FAME (37-55\%) than the lipids in the ARID pond culture (56-84\%). Analogous to biomass productivities, the volumetric lipid productivity in

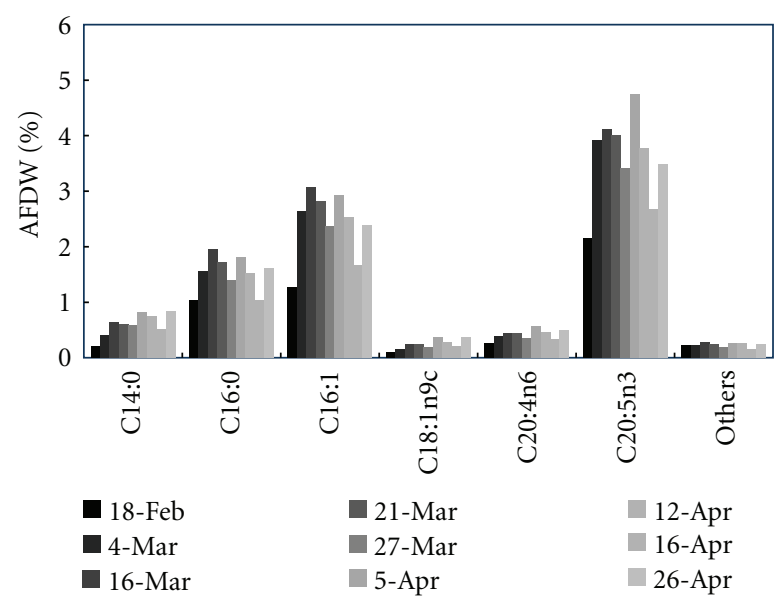

FIGURE 9: FAME composition of the conventional raceways, as a percentage of ash free dry weight. The Others category includes C14:1, C20:0, C18:0, C18:1, C18:2n6c, C20:1, C18:3n3, C20:2, C22:0, C22:1n9, C20:3n3, C24:1, C22:6n3, and C24:0.

the ARID culture was twice as high as in the conventional raceways, while both culture systems exhibited similar areal productivities (Table 2 ).

The change in FAME composition in the ARID pond and conventional raceways is shown as a function of time in Figures 8 and 9, respectively. Palmitic (C16:0), palmitoleic (C16:1), and eicosapentaenoic (EPA, C20:5n3) acids comprised around $80 \%$ of all measured FAMEs in both culture systems, with the remainder composed predominantly of myristic (C14:0), oleic (C18:1n9c), and arachidonic (C20:4n6) acids. The remaining FAMEs comprised less than $1 \%$ of biomass (AFDW) for all analyzed samples. In the ARID pond, C16:0 and C16:1 content generally increased with increasing culture age, while the concentration of $\mathrm{C} 20: 5 \mathrm{n} 3$ decreased. Oleic acid $(\mathrm{C} 18: 1 \mathrm{n} 9 \mathrm{c})$ reached its highest concentration (1.3\% g FAME/g biomass) in the ARID pond on $2 / 18$, while remaining below $0.5 \%$ in all other samples taken from both culture systems. There were no significant changes in the FAME composition in the conventional raceways (Figure 9). EPA was always found in higher concentrations than $\mathrm{C} 16: 0$ or $\mathrm{C} 16: 1$ in the conventional raceways (Figure 7), whereas the shorter-chain C16 fatty acids reached higher concentrations relative to EPA in the ARID pond on 2/24 (Figure 8). 


\section{Discussion}

The ARID pond temperature management system succeeded in buffering temperature extremes. Both culture systems were challenged on $2 / 3$ when the ambient low temperature reached $-7.8^{\circ} \mathrm{C}$, within $1^{\circ} \mathrm{C}$ of Tucson's all-time February low temperature of $-8.3^{\circ} \mathrm{C}$ in 1899 [16]. Extreme ambient temperatures and strong winds led to pond water temperatures decreasing to $-1.8^{\circ} \mathrm{C}$ for two consecutive days in the conventional raceways (Figure 2(d)). Over the same period, the ARID pond maintained water temperatures above $12^{\circ} \mathrm{C}$ by keeping the algal culture in the deep canal during the day, rather than circulating it into the shallow basins. The resulting warmer temperatures allowed the ARID culture to have a 10-day shorter lag phase than the conventional raceways. While the ARID pond temperature management system failed to raise pond water temperatures to the level where N. salina exhibit optimum growth kinetics $\left(27-29^{\circ} \mathrm{C}\right)$, it succeeded in maintaining average pond water temperatures greater than both the ambient air temperature and water temperatures of the conventional raceways $[17,18]$.

Improved volumetric productivities observed in the ARID culture indicate that its operation strategy had a positive effect on biomass accumulation. It is difficult, however, to conclusively determine whether increased pond water temperatures or shallow culture depth was the primary driver. The inherent ARID pond dimensions, with shallow basins draining into a deep canal, made it impossible to achieve identical culture depths in the conventional raceways. Nevertheless, given that Van Wagenen et al. [18] showed that the maximum specific growth rate of $N$. salina under nonshaded and nutrient replete conditions was nearly three times higher at $19.5^{\circ} \mathrm{C}$ (the average water temperature in the ARID pond) than at $14.0^{\circ} \mathrm{C}$ (the average water temperature in the conventional raceways), that is, 0.54 and 0.17 day $^{-1}$, respectively; the average $5.5^{\circ} \mathrm{C}$ temperature difference between the ARID pond and the conventional raceways must have been to a large part responsible for increased volumetric biomass productivity in the ARID pond.

Despite the ARID culture's improved volumetric productivity, similar areal productivities $\left(3.47\right.$ versus $3.34 \mathrm{~g} \mathrm{~m}^{-2}$ day $^{-1}$, resp.) indicate that its design or operation strategy can be optimized to take full advantage of its temperature management system. Shallow basins in the ARID pond culture led to a higher proportion of cells receiving light above saturating intensities, which contributed to its higher volumetric productivity relative to the conventional raceways. In order to increase areal productivities, the ARID pond should be operated so that the areal quantum yield is optimized; that is, the biomass yield for each photon per unit area is increased by either increasing culture depth or by operating at higher cell densities. Increasing culture depth will increase culture volume per unit area, thereby increasing the areal productivity. Similarly, increasing cell density such that the average light intensity per cell is equal to the saturating light intensity at the bottom of the shallow basins can also increase areal productivity. Given the ARID culture's low current velocity and nearly laminar flow (Table 1), it may be necessary to increase mixing to avoid problems (i.e., thermal and chemical stratification, unstable cultures) associated with poorly mixed cultivation systems [19].

Indoor laboratory studies on lipid and fatty acid synthesis offer the flexibility to vary individual chemical stimuli or environmental conditions to observe effects independently; outdoor studies offer no such option. However, given that large-scale biofuel production will likely occur in an outdoor setting with limited control of environmental conditions, it is important to consider the effects of interacting growth parameters. Factors including water temperature, incident light intensity, nutrient concentration, salinity, and growth phase (i.e., lag, exponential, or linear) have been shown to influence lipid and fatty acid content and composition $[18,19]$. Furthermore, average cellular light intensity is a function of incident light intensity, culture depth, and biomass concentration [20, 21]; seasonal and day-to-day variations alone do not fully describe light penetration depth. Therefore, differences in lipid and fatty acid content and composition as both functions of time and cultivation system can be attributed to a variety of factors.

Whereas lipid content in the ARID culture varied, the steady increase in lipid and fatty acid content in the conventional raceways until $3 / 14$ can be attributed to several contributing factors. Between $2 / 18$ and 3/14, there was nearly a doubling in both lipid and fatty acids content in the conventional raceways. Given that increasing solar radiation, warming water temperatures, and phosphate limitation $(2 / 25)$ occurred during this period, their combined effects likely resulted in the steady increase in lipids and fatty acids. All have been shown to increase fatty acid and lipid content in Nannochloropsis; a rise in culture temperature [17], phosphate limitation [22, 23], and light intensity [2426]. After $3 / 14$, trends become difficult to discern. Variability in the lipid content analysis (3\% s.d.) may also complicate data interpretation, as small changes in lipid content may be more appropriately assigned to experimental error than responses to physical or chemical phenomena. Fatty acid content varies from 8.5 to $11.5 \%$ after $3 / 14$, but more data points would be needed to discern trends possibly associated with day-to-day environmental variations.

Given that TAGs comprised a consistently higher proportion of total lipids in the ARID pond than in the conventional raceways (i.e., $55-85 \%$ versus $36-54 \%$ ), either the ARID culture's relatively shallower basin depth (17.5 versus $25 \mathrm{~cm})$ or warmer water temperatures $\left(14.5\right.$ versus $\left.20^{\circ} \mathrm{C}\right)$ likely played a role. Sukenik and Carmeli [25] reported lipids with higher proportions of fatty acids in light sufficient cultures. Therefore, the more shallow basins of the ARID culture likely increased the amount of time cells spent in the light sufficient regions of the pond, leading to increased proportions of fatty acids in cellular lipids. Increased temperatures have also been demonstrated to increase fatty acid and lipid content in commercial scale cultures $[17,27]$, although it was unclear whether the proportion of fatty acids in lipids similarly increases. Also, there have been contradicting observations relating temperature and light fluctuations to lipid content in laboratory and outdoor cultures, preventing a simple explanation of trends $[27,28]$. 
In regards to fatty acid composition, algae in both ponds displayed the high proportions of palmitic, palmitoleic, and eicosapentanoic acids characteristic of $N$. salina $[29,30]$. There were, however, differences in the relative levels of these three fatty acids between the two cultivation systems. In the conventional raceways, despite fluctuating fatty acid content, the fatty acid composition remained nearly constant through batch growth, with higher $\mathrm{C} 20: 5 \mathrm{n} 3$ content relative to C16 and C16:1. In a study conducted by Sukenik et al. [28], Nannochloropsis sp. grown semicontinuously in paddlewheel-driven open ponds $(20 \mathrm{~cm}$ culture depth) at similar water temperatures to our conventional raceways (10.5 to $16.8^{\circ} \mathrm{C}$ versus $14.5^{\circ} \mathrm{C}$ daily average, resp.) yielded similar concentrations of the three main fatty acids, C16, C16:1, and C20:3n5. The observed fatty acid profile may therefore be characteristic of outdoor Nannochloropsis cultures grown in winter conditions in a similar reactor geometry.

In contrast to the conventional raceways, the fatty acid profile in the ARID pond varied during the batch growth phase. Initially, biomass was characterized by a higher percentage of C20:3n5 than C16 or C16:1. After 2/24, the C16 fatty acids were measured in greater amounts than C20:3n 5 . Variations in fatty acid content are often due to a form of stress (i.e., high average cellular light intensity, nutrient limitation, growth phase transition, temperature) $[20,21]$. As in our study, Hodgson et al. [31] also observed an increase of C16 and C16:1 with a concomitant decrease of C20:5n3 during the stationary growth phase in a nitrate-limited culture. Other authors have also noted decreases in polyunsaturated fatty acids in response to nitrate limitation $[22,26]$ increasing solar radiation $[25,26]$ or temperature [32].

\section{Conclusions}

Mitigation of temperature extremes and increased daily average temperatures led to increased biomass production in the ARID culture. The ARID culture system successfully increased pond water temperatures relative to the conventional raceways, decreasing the time required to reach the stationary phase by 27 days. Despite increased volumetric productivity in the ARID pond, its areal productivity was similar to that of the conventional raceways (3.47 versus $3.34 \mathrm{~g} \mathrm{~m}^{-2}$ day $^{-1}$ ), suggesting that the ARID pond design can be further optimized, most likely by increasing the culture depth or operating at higher biomass densities. In either case, it may be necessary to increase turbulence to avoid problems associated with poor mixing.

\section{Acknowledgments}

The author(s) would like to acknowledge funding of this work by the US Department of Energy under Contract DEEE0003046 awarded to the National Alliance for Advanced Biofuels and Bioproducts.

\section{References}

[1] W. Oswald, "Current status of algae from wastes," Chemical Engineering Symposium Series, vol. 65, pp. 87-92, 1969.
[2] D. Chaumont, "Biotechnology of algal biomass production: a review of systems for outdoor mass culture," Journal of Applied Phycology, vol. 5, no. 6, pp. 593-604, 1993.

[3] E. Becker, Microalgae. Biotechnology and Microbiology, Cambridge University Press, Cambridge, UK, 1994.

[4] C. H. Su, L. J. Chien, J. Gomes et al., "Factors affecting lipid accumulation by Nannochloropsis oculata in a two-stage cultivation process," Journal of Applied Phycology, vol. 23, no. 5, pp. 903-908, 2011.

[5] B. Pushparaj, E. Pelosi, M. R. Tredici, E. Pinzani, and R. Materassi, "An integrated culture system for outdoor production of microalgae and cyanobacteria," Journal of Applied Phycology, vol. 9, no. 2, pp. 113-119, 1997.

[6] R. Ryan, P. Waller, M. Kacira, and P. Li, "Aquaculture raceway integrated design,” US Patent 0023360 A1, 2011.

[7] P. Waller, R. Ryan, M. Kacira, and P. Li, "The algae Raceway integrated design for optimal temperature management," Journal of Biomass and Bioenergy. In press.

[8] I. Setlik, S. Veladimir, and I. Malek, "Dual purpose open circulation units for large scale culture of algae in temperature zones. I. Basic design considerations and scheme for pilot plant," Algological Studies, vol. 1, pp. 111-164, 1970.

[9] R. R. Guillard and J. H. Ryther, "Studies of marine planktonic diatoms. I. Cyclotella nana Hustedt, and Detonula confervacea (cleve)," Canadian Journal of Microbiology, vol. 8, pp. 229-239, 1962.

[10] http://www.instantocean.com/.

[11] M. H. Huesemann, T. S. Hausmann, R. Bartha et al., "Biomass productivities in wild type and pigment mutant of Cyclotella sp. (Diatom)," Applied Biochemistry and Biotechnology, vol. 157, no. 3, pp. 507-526, 2009.

[12] Product no. 2106103, http://www.hach.com/.

[13] Product no. 2106103, http://www.hach.com/.

[14] E. G. Bligh and W. J. Dyer, "A rapid method of total lipid extraction and purification.," Canadian Journal of Biochemistry and Physiology, vol. 37, no. 8, pp. 911-917, 1959.

[15] W. Christie and X. Han, Lipid Analysis-Isolation, Separation, Identification and Lipidomic Analysis, The Oily Press, Bridgwater, UK, 2010.

[16] February 2011 climate report for Tucson, National Weather Service Forecast Office, Tucson AZ, 2011, http://www.wrh .noaa.gov/twc/climate/monthly/feb11.php.

[17] S. Boussiba, A. Vonshak, Z. Cohen, Y. Avissar, and A. Richmond, "Lipid and biomass production by the halotolerant microalga Nannochloropsis salina," Biomass, vol. 12, no. 1, pp. 37-47, 1987.

[18] J. van Wagenen, S. Hobbs, P. Hooke, B. Crowe, and M. Huesemann, "Effect of light intensity and temperature on growth rate and fatty acid composistion in Nannochloropsis salina," Energies, no. 3, pp. 731-740.

[19] M. Borowitza, "Culturing microalgae in outdoor ponds," in Algal Culturing Techniques, R. Andersen, Ed., pp. 205-218, Elsevier Academic Press, Burlington, Mass, USA, 2005.

[20] Q. Hu, M. Sommerfeld, E. Jarvis et al., "Microalgal triacylglycerols as feedstocks for biofuel production: perspectives and advances," Plant Journal, vol. 54, no. 4, pp. 621-639, 2008.

[21] P. Leonardi, C. Popovich, and M. Damiani, Feedstocks for Second-Generation Biodiesel: Microalgae's Biology and Oil Composition, Economic Effects of Biofuel Production, 2011, http://www.intechopen.com/articles/show/title/feedstocksfor-second-generation-biodiesel-microalgae-s-biology-andoil-composition.

[22] H. Hu and K. Gao, "Response of growth and fatty acid compositions of Nannochloropsis sp. to environmental factors 
under elevated $\mathrm{CO}_{2}$ concentration," Biotechnology Letters, vol. 28, no. 13, pp. 987-992, 2006.

[23] L. Rodolfi, G. C. Zittelli, N. Bassi et al., "Microalgae for oil: strain selection, induction of lipid synthesis and outdoor mass cultivation in a low-cost photobioreactor," Biotechnology and Bioengineering, vol. 102, no. 1, pp. 100-112, 2009.

[24] S. M. Renaud, D. L. Parry, L. V. Thinh, C. Kuo, A. Padovan, and N. Sammy, "Effect of light intensity on the proximate biochemical and fatty acid composition of Isochrysis sp. and Nannochloropsis oculata for use in tropical aquaculture," Journal of Applied Phycology, vol. 3, no. 1, pp. 43-53, 1991.

[25] A. Sukenik and Y. Carmeli, "Regulation of Fatty Acid Composition by Irradiance Level in the Eustigmatophyte Nannochloropsis sp.," Journal of Phycology, vol. 25, pp. 686692, 1989.

[26] D. Pal, I. Khozin-Goldberg, Z. Cohen, and S. Boussiba, "The effect of light, salinity, and nitrogen availability on lipid production by Nannochloropsis sp.," Applied Microbiology and Biotechnology, vol. 90, no. 4, pp. 1429-1441, 2011.

[27] A. Converti, A. A. Casazza, E. Y. Ortiz, P. Perego, and M. del Borghi, "Effect of temperature and nitrogen concentration on the growth and lipid content of Nannochloropsis oculata and Chlorella vulgaris for biodiesel production," Chemical Engineering and Processing: Process Intensification, vol. 48, no. 6, pp. 1146-1151, 2009.

[28] A. Sukenik, O. Zmora, and Y. Carmeli, "Biochemical quality of marine unicellular algae with special emphasis on lipid composition. II. Nannochloropsis sp.", Aquaculture, vol. 117, no. 3-4, pp. 313-326, 1993.

[29] J. Volkman, M. Brown, G. Dunstan, and S. Jeffrey, "Biochemical composition of marine microalgae from the class Eustigmatophyceae," Journal of Phycology, vol. 29, pp. 69-78, 1993.

[30] I. Khozin-Goldberg and S. Boussiba, "Concerns over the reporting of inconsistent data on fatty acid composition for microalgae of the genus Nannochloropsis (Eustigmatophyceae)," Journal of Applied Phycology, vol. 23, no. 5, pp. 933 934, 2011.

[31] P. A. Hodgson, R. J. Henderson, J. R. Sargent, and J. W. Leftley, "Patterns of variation in the lipid class and fatty acid composition of Nannochloropsis oculata (Eustigmatophyceae) during batch culture," Journal of Applied Phycology, vol. 3, no. 2, pp. 169-181, 1991.

[32] A. Sukenik, Y. Yamaguchi, and A. Livne, "Alterations in lipid molecular species of the marine eustigmatophyte Nannochloropsis sp.," Journal of Phycology, vol. 29, no. 5, pp. 620626, 1993. 

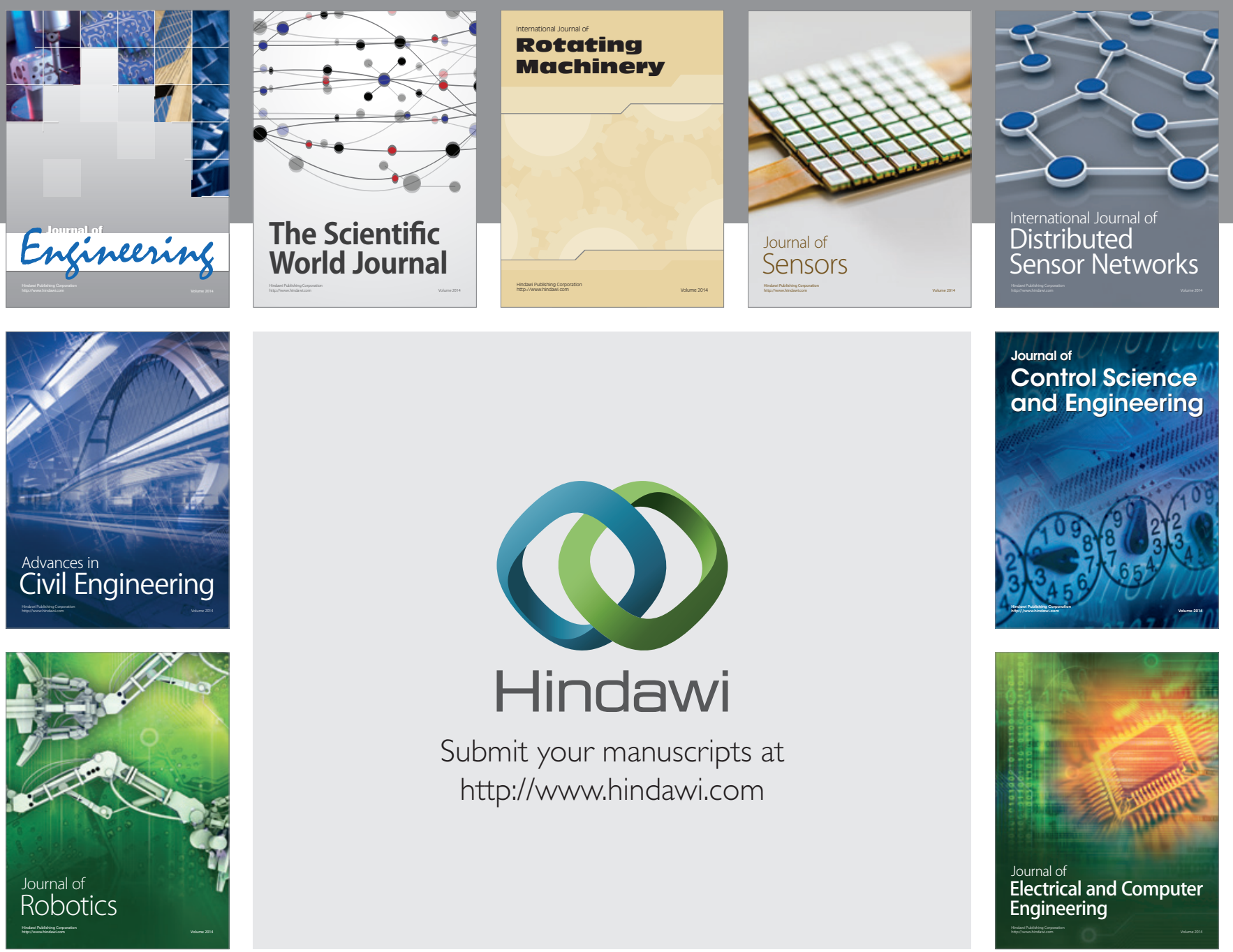

Submit your manuscripts at

http://www.hindawi.com
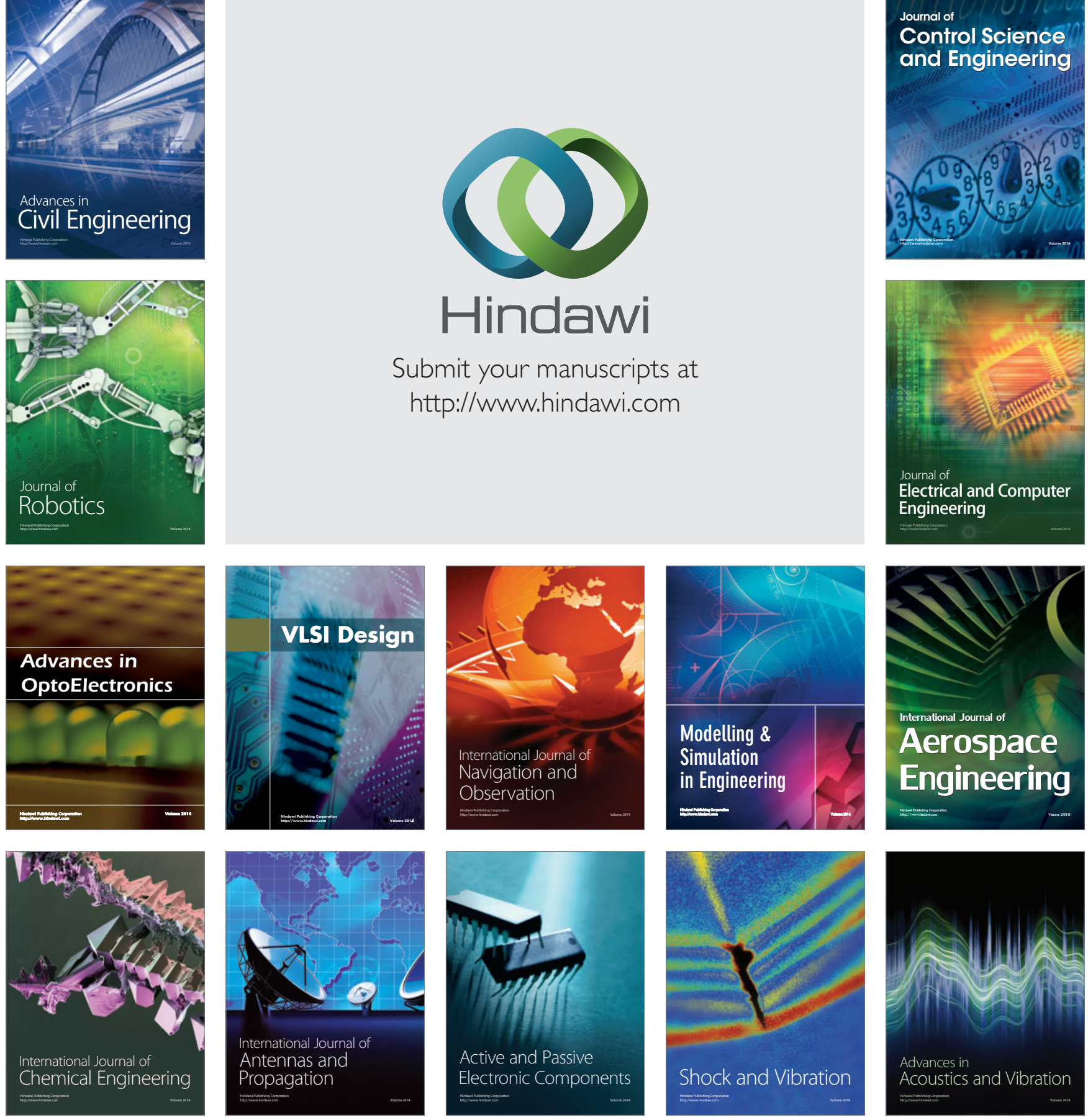